\title{
La política exterior de Chile durante los gobiernos de la Concertación (1990-2010)
}

\author{
Alberto van Klaveren ${ }^{*}$
}

Las políticas exteriores no surgen de la nada. Ellas suelen tener orígenes más próximos y otros más remotos. En el caso de Chile, qué duda cabe, los factores explicativos más cercanos se centran a comienzos de la década de 1990, indisolublemente ligados a la recuperación de la democracia después de un período dictatorial que tuvo un impacto muy negativo en sus relaciones internacionales oficiales. El retorno democrático no solo permitió la plena reinserción internacional de Chile sino que hizo posible una activa política de negociaciones comerciales internacionales que permitió potenciar la apertura económica iniciada durante el régimen autoritario. La reinserción internacional del país se combinó con una tradición histórica acumulada a lo largo de más de un siglo y medio de vida

Profesor titular, Universidad de Chile; Embajador y ex Subsecretario de Relaciones Exteriores de Chile independiente, en que se plasmaron algunos principios básicos que habían marcado la proyección externa del país y que se reflejaron especialmente en las definiciones territoriales, las relaciones con las naciones vecinas y la participación de Chile en una serie de instituciones internacionales. Todo ello, en el contexto de los grandes cambios políticos y económicos que se registraron en el escenario internacional y que tuvieron un impacto muy decisivo en la política exterior y en la propia sociedad chilena, más allá de los procesos internos que se vivieron en el país.

El propósito de este artículo es presentar un panorama de las transformaciones que han experimentado las relaciones exteriores durante los gobiernos de la Concertación, la coalición de centroizquierda que presidió la transición y normalización democrática de Chile y que se mantuvo en el poder entre los años 1990 y 2010. Más que 
hacer un recuento cronológico de la evolución de la política exterior, interesa identificar las principales áreas de cambio y registrar los desafíos y las tendencias emergentes que se proyectan en la actualidad.

\section{LA POLÍTICA VECINAL: LAS DOS AGENDAS}

A partir de los años noventa Chile emprendió una política de acercamiento con las naciones vecinas y con el resto de América Latina de una manera pragmática y realista, con la certeza de que ya no era posible diseñar estrategias aislacionistas. Los gobiernos de la Concertación estimaron que una política exterior estable requería de relaciones satisfactorias con los países vecinos. Para la seguridad nacional y para un desarrollo sostenido resultaba esencial despejar todos los remanentes conflictivos del pasado y construir profundos vínculos económicos, políticos y culturales que llevaran a un ambiente vecinal de confianza mutua y cooperación. Se comenzó a hablar de una «política vecinal» precisamente para describir una política que apuntaba a superar antiguas cuestiones limítrofes pendientes con pleno apego a los principios tradicionales mantenidos en ese ámbito y que pretendía proporcionar un nuevo marco a las relaciones de creciente interdependencia con el entorno natural de Chile. Se trataba de buscar una relación vecinal estable y consolidada, basada en acuerdos claros que fueran eliminando los problemas pendientes y que actuaban como obstáculos para una integración moderna y efectiva.

La agenda con los países vecinos incluyó temas tradicionales y nuevos. Los primeros decían relación con los temas limítrofes. Los segundos se referían al eje de interdependencia y cooperación que se estaba fortaleciendo visiblemente, impulsado principalmente por el propio desarrollo económico del país y las tendencias hacia la regionalización y la globalización presentes en su economía. Así, la agenda histórica se combinó con una agenda de integración, entendida esta última no como una apuesta política por un proyecto utópico, sino como la consecuencia de fenómenos económicos y sociales más bien autónomos de la acción del gobierno, en que las fuerzas motoras eran los empresarios o, en menor medida, las regiones del país.

En ninguna relación bilateral de Chile se expresaron de manera tan nítida las realidades de la interdependencia como en la vinculación con Argentina. En un marco de relaciones cada vez más densas y múltiples, la política exterior de la Concertación desplegó grandes esfuerzos para producir un vuelco sustancial en una relación bilateral signada históricamente por desencuentros periódicos y desconfianza mutua. En ese contexto, resultaba obvia la necesidad de superar diferendos limítrofes que tradicionalmente habían tensionado las relaciones bilaterales y que en tiempos recientes habían llevado a los dos países al borde de la guerra. En agosto de 1990, los Presidentes Aylwin y Menem 
tomaron la iniciativa de identificar todas las cuestiones limítrofes aún pendientes entre Argentina y Chile, con el fin de encontrar una solución definitiva para ellas. Después de una intensa labor, se identificaron 24 problemas vinculados a la demarcación del límite internacional. Mediante una Declaración Presidencial sobre Límites adoptada por ambos mandatarios en Buenos Aires el 2 de agosto de 1991, 22 problemas fueron resueltos directamente. La controversia de Laguna del Desierto fue sometida al arbitraje internacional, de conformidad con lo dispuesto en el Tratado de Paz y Amistad de 1984. En 1994 un tribunal especial emitió un fallo que fue enteramente favorable a la Argentina. Este fallo representó un episodio doloroso y duro para el gobierno. Aunque las críticas por este resultado arreciaron, las relaciones con Argentina se siguieron intensificando $y$, significativamente, ningún sector cuestionó este desarrollo. El último diferendo presente, la demarcación del límite comprendido entre el Monte Fitz Roy y el Cerro Daudet, conocido como Campos de Hielos Sur en Chile y Hielos Continentales en Argentina, fue remitido, después de una larga y compleja negociación, a un Acuerdo aprobado entre ambos gobiernos, que fue ratificado en 1999.

Mas las relaciones entre Chile y Argentina distaron mucho de reducirse solo a la agenda limítrofe histórica. Durante los últimos veinte años se produjo un verdadero salto cualitativo en la relación bilateral, que tuvo sus raíces en el Tratado de Paz y Amistad de 1984. El comercio bilateral aumentó de manera notable, aunque mantuvo una tendencia algo cíclica. Parte de los cientos de miles de ciudadanos de origen chileno que viven en la Argentina se vieron beneficiados por programas de regularización e integración social en ese país. El turismo desde el país vecino se convirtió en una fuente de ingresos de gran significación para Chile, perfectamente comparable a los rubros de exportación más dinámicos que exhibía el país. Chile se convirtió, a través de sus empresarios, en una de las principales fuentes de inversiones extranjeras en Argentina. Asimismo, ambos países suscribieron en 1997 un importante acuerdo sobre Integración Minera que ofreció un nuevo marco al sector minero de ambos países. En materia de integración física, cabe destacar la puesta en práctica del Plan Maestro de Pasos Fronterizos con el propósito de habilitar o reforzar todos los servicios fiscales en un número creciente de pasos, así como el desarrollo de proyectos para la construcción de túneles transandinos que mejoren la conectividad entre ambos países y permitan un mejor acceso de los usuarios argentinos y de otros países atlánticos a los puertos del Pacífico chileno. Cabe destacar también el papel central que han desempeñado las regiones y provincias de los dos países en la densificación de la relación bilateral.

A partir de 1991 también se produjo una considerable integración energética entre ambos países, que se tradujo en la 
construcción de diversos gasoductos, a través de los cuales Argentina exportó grandes cantidades de gas a Chile, en un flujo que empezó a reducirse de manera abrupta a partir de 2004, cuando el gobierno argentino decretó restricciones cada vez mayores a sus exportaciones con el fin de dar preferencia a un abastecimiento interno crecientemente difícil. Estas restricciones se transformaron en el principal problema bilateral entre ambos países durante los años que siguieron, llevando a Chile a buscar fuentes alternativas de abastecimiento. Sin embargo, pese a las críticas permanentes de los medios de comunicación, de sectores de la oposición e incluso de parlamentarios que los apoyaban, los gobiernos de los Presidentes Lagos y Bachelet logaron evitar que las relaciones entre ambos países se "gasificaran" y así mantener el proceso histórico de acercamiento entre ambos países, que adquirió una dimensión especial en el sensible ámbito de la defensa, en que se estableció una Fuerza de Paz Conjunta Combinada, con su propio Estado Mayor, bajo el nombre "Cruz del Sur". Como culminación de este acercamiento, a fines del 2009 las Presidentas de ambos países firmaron el Tratado de Maipú de Integración y Cooperación.

Especialmente durante la década de 2000, coincidiendo con importantes cambios políticos en Bolivia, Chile logró un mejoramiento histórico de sus relaciones con ese país, creando espacios adecuados de diálogo para tratar los distintos temas de la agenda bilateral. Pese a que las relaciones diplomá- ticas oficiales siguieron interrumpidas, los encuentros presidenciales se multiplicaron y el Mecanismo Permanente de Consultas Políticas, establecido en 1994, funcionó con una regularidad admirable. El comercio bilateral se rigió por un Acuerdo de Complementación Económica que contempló concesiones no recíprocas por parte de Chile con el fin de atenuar el déficit comercial que lo favorece. Se promovió una mayor integración física, se mejoraron los controles fronterizos y se desarrolló una importante cooperación bilateral. En el marco del régimen de libre tránsito establecido a favor de Bolivia, se registró un aumento en el monto de carga boliviana que pasa por territorio chileno y un uso creciente de puertos chilenos para el intercambio de bienes bolivianos con el exterior.

Por cierto, durante todo este período Bolivia mantuvo su aspiración a una salida soberana al mar como uno de los objetivos prioritarios de su política exterior. Esta demanda histórica no disminuyó en importancia, sin perjuicio de que las sucesivas administraciones del país vecino la hayan definido y formulado de manera variable a lo largo de estas dos décadas. Tampoco disminuyó la extrema sensibilidad que demuestra Bolivia en la conducción de sus relaciones bilaterales con Chile, factor que ha estado presente en virtualmente todos los procesos de acercamiento mutuo que se han emprendido. Ni han estado ausentes los problemas de expectativas y de percepciones mutuas contradictorias. Pero, más allá de estos matices, es 
innegable que la evolución de las relaciones bilaterales estuvo condicionada por los cambios políticos en ese país y la llegada al poder de una verdadera contraélite en La Paz, representativa de un vasto sector de la población boliviana tradicionalmente marginado de las grandes decisiones del país. Esa contraélite, bajo la conducción del Presidente Evo Morales, permitió desarrollar y profundizar una agenda concreta bilateral, conocida como la agenda de los 13 puntos, en la que Chile aceptó incluir el tema marítimo, como una forma de sincerar el diálogo y abordar sin condiciones previas y con espíritu abierto todos los temas relevantes de la agenda bilateral.

En cuanto a Perú, el tercer vecino, se puede afirmar que en ninguna otra relación de Chile han convivido de manera tan central y tan cruda las dos agendas de sus relaciones vecinales: la agenda histórica, centrada en temas territoriales, conflictos pretéritos y consideraciones de balanza del poder, $\mathrm{y}$ la agenda positiva, centrada en una interdependencia económica creciente en una perspectiva de futuro. El equilibrio entre ambas agendas fue especialmente frágil durante el período, sucediéndose permanentemente ciclos de acercamiento y distanciamiento.

En el ámbito de los temas más históricos, se logró resolver en 1999 los puntos pendientes en el Tratado de 1929 entre Chile y Perú y su protocolo complementario, consistentes en la construcción en la bahía de Arica, para el servicio del Perú, de un malecón de atraque, una oficina para la Aduana peruana y una estación para el ferrocarril a Tacna. Aunque este logro fue presentado en ambos países como el último tema pendiente en el ámbito territorial y como una especie de cierre histórico de las tensiones que habían existido entre ambos países desde la época de la Guerra del Pacífico en el siglo XIX, el año 2008 Perú presentó una demanda contra Chile ante la Corte Internacional de Justicia reclamando una delimitación marítima que Chile consideraba plenamente establecida desde comienzos de los años cincuentao, cuando ambos países, junto a Ecuador, proclamaron su soberanía y jurisdicción sobre sendas zonas marítimas de 200 millas marinas. Aunque Perú recalcó la necesidad de mantener este caso judicial en una cuerda separada respecto de la relación bilateral general, a Chile no le fue indiferente haber sido llevado por primera vez en su historia a la Corte de La Haya para dirimir un asunto que estimaba y sigue estimando plenamente resuelto.

Pese a ello, la relación económica entre ambos países se potenció significativamente durante las últimas décadas. La recuperación de la economía peruana y el proceso de privatizaciones que se desarrolló durante los últimos años generaron nuevas y grandes oportunidades para los vínculos económicos bilaterales. El comercio entre los dos países creció considerablemente. También se observó un creciente flujo migratorio desde Perú hacia Chile, el que fue acogido muy razonablemente 
por la sociedad chilena y cuyo sector informal se vio beneficiado por sucesivas regularizaciones. El país vecino se convirtió igualmente en un destino muy importante de las inversiones chilenas en el extranjero. Las frecuencias aéreas y el turismo entre ambos países se intensificaron. Chile y Perú suscribieron en 1998 un acuerdo de libre comercio, que recientemente fue profundizado.

\section{LA POLÍTICA}

LATINOAMERICANA: LA

DIFICIL BÚSQUEDA DE UN

\section{REGIONALISMO RENOVADO}

Hasta la década de 1970, Chile exhibía una larga trayectoria en el campo de la integración latinoamericana y desempeñaba un papel de liderazgo en iniciativas como el propio Pacto Andino. Sin embargo, la evaluación de estas experiencias, los problemas políticos que afectaron al país durante los años setenta y ochenta, las características del modelo económico y los cambios que se habían producido en el entorno regional y mundial, llevaron a una modificación de las concepciones tradicionales frente a la integración latinoamericana.

Por cierto, Chile continuó manteniendo relaciones estrechas con el resto de la región, que no se limitaron tan solo al plano comercial. La participación de los países latinoamericanos en el comercio exterior chileno se mantuvo relativamente estable durante las décadas de la Concertación. Como los prin- cipales mercado para las exportaciones están fuera de la región, la balanza comercial con América Latina ha sido tradicionalmente deficitaria para Chile. Además, la región empezó a representar un mercado fundamental para las exportaciones chilenas de mayor valor agregado, tendencia que naturalmente ha estado condicionada a los ciclos económicos de América Latina.

A partir de 1990 Chile negoció una cadena de acuerdos orientados hacia la creación de espacios de libre comercio, la promoción de la integración física y energética y el desarrollo de nuevas formas de cooperación regional. Se trató de avanzar sostenidamente en la línea de estos acuerdos, pero teniendo muy en claro que la apertura comercial chilena al mundo era irrenunciable y que el país no podía asumir opciones de integración que significaran elevar los aranceles del país u obstaculizar la negociación de acuerdos comerciales con otras regiones.

En términos más generales, se consideró que la integración regional no debía ser solo el producto de la voluntad política ni orientarse hacia el logro de metas muy ambiciosas que en definitiva no podrían cumplirse. Por el contrario, ella requería de flujos de comercio de bienes y servicios verdaderamente significativos, de la adopción de políticas económicas compatibles, de la estabilidad económica de los socios, de la disposición a someterse a mecanismos y disciplinas colectivas y de una convicción profunda de que los esquemas de integración debían estimular la competitividad. 
Chile buscó, con éxito variable, alianzas estratégicas para participar en el sistema internacional en mejores condiciones de competitividad y de presencia mundial. Este énfasis regional se reflejó en la negociación de ambiciosos acuerdos de libre comercio o de asociación estratégica, con países como México, América Central, Colombia, Ecuador y Perú. Esta política también se orientó hacia agrupaciones subregionales como MERCosUR, espacio de concertación de gran relevancia económica y política para Chile, y la Comunidad Andina, proyecto de integración en que Chile había sido socio fundador.

Aparte de los países vecinos, dos naciones latinoamericanas ocuparon un lugar fundamental en la redefinición de la política latinoamericana de Chile. La primera fue Brasil, que había ocupado tradicionalmente un lugar de gran importancia en las relaciones internacionales de Chile, tanto en términos políticos como económicos. Esa relevancia se vio confirmada durante las últimas décadas. En el ámbito económico, Brasil se situó entre los principales socios comerciales de Chile y se convirtió en un destino muy atrayente para sus inversiones en el extranjero. En los últimos años, diversos grupos económicos brasileños han empezado a invertir en el mercado chileno. En el ámbito político se estructuró un nuevo entendimiento bilateral, que se vio estimulado por las fuertes coincidencias que se observaron entre las administraciones Lagos y Cardoso y Bachelet y Lula.
Por su parte, Chile y México consolidaron una importante relación bilateral. A ello contribuyó un tratado de libre comercio de última generación, el dinamismo de ambas economías, la existencia de importantes coincidencias de política exterior entre ambos países y políticas comerciales aperturistas y activas.

A partir de los años noventa, Chile comenzó a desarrollar programas de cooperación horizontal con los países de América Central y el Caribe. La Agencia de Cooperación Internacional de Chile (AGCI) se convirtió en el instrumento para llevar a cabo esta política, aunque en sus inicios ella puso mucho más acento en la recepción que en el otorgamiento de cooperación internacional. Dotados de recursos obviamente modestos, los programas de cooperación horizontal lograron cierta visibilidad y generaron un estrechamiento notable de los vínculos con América Central y el Caribe.

En el plano regional, Chile participó activamente en el Grupo de Río, volviendo a ocupar, por segunda vez en el período en comento, su Secretaría Pro Tempore a partir de febrero de 2010, apoyando su papel de interlocución con el resto del mundo y respetando la creciente diversidad de sus miembros. Pero lo más novedoso durante el período consistió en la activa participación que le cupo a Chile en el establecimiento de la Unión de Naciones Suramericanas (UNASUR), cuya institucionalidad se fue estableciendo a partir de 2005 en un proceso complejo en que se tuvieron que conciliar posiciones muy diferen- 
tes de los países, desde el activismo revolucionario de Venezuela hasta las reticencias de Colombia, en un contexto marcado por varias disputas bilaterales y concepciones antagónicas en materia de integración regional y modelos políticos y económicos. Así, mientras algunos países seguían concibiendo la integración como un proceso gradual con una vertiente comercial de liberalización y otra política de concertación, otros veían a UNASUR como una unión eminentemente política, con una cierta cesión de soberanía pero dejando de lado cualquier esquema de liberalización. Chile, que favorecía un enfoque más gradual, terminó ocupando la Secretaría Pro Tempore de UNASUR durante los años 2008 y parte de 2009. En esa calidad, aportó a la creación de una institucionalidad basada en el consenso y destinada a generar un espacio flexible de integración en lo político, social, cultural y económico, otorgando prioridad al diálogo político, las políticas sociales, la educación, la energía, la infraestructura, la defensa, el medio ambiente y el financiamiento. La Secretaría chilena, a través de la propia Presidenta Bachelet, también tuvo un papel activo de mediación en la crisis política que afectó a Bolivia el año 2008.

Chile también participó en la Cumbre de América Latina y Caribe (CALC), concebida como un nuevo espacio político destinado a contribuir a la integración regional entre todos los Estados de América Latina y el Caribe. En la medida en que la membresía del Grupo de Río se fue ampliando hasta aproximarse a aquella del calc, la diplomacia chilena favoreció una imbricación entre ambas iniciativas, dentro de un marco de flexibilidad y gradualidad, evitando una institucionalización prematura. Algunos países de la región no compartieron ese enfoque, favoreciendo la creación de una nueva institución, cuya relación con la Organización de los Estados Americanos (oEA), entidad con más de un siglo de historia y dotada de una institucionalidad muy robusta, no ha sido precisada. Algunos países ven en esa nueva estructura una alternativa frente a una Organización en la que participa Estados Unidos. Otros parecen ver el nuevo proyecto como un complemento a la oeA. Sea como fuere, esta nueva creatividad institucional todavía no parece cristalizarse. Por lo mismo, la política exterior chilena ha seguido esta tendencia con cierta prudencia, manifestando su apoyo a todos los mecanismos de concertación regional, pero expresando sus reservas sobre la creación de nuevas entidades, más allá de UNASUR.

Los gobiernos de la Concertación impulsaron una política prudente y gradual de acuerdos en materia de seguridad regional, que incluía pasos progresivos, antes que esquemas demasiado amplios, ambiciosos o abstractos que no parecían viables. En consecuencia, Chile contribuyó activamente, junto a Argentina y Brasil, a la reforma del Tratado de Tlatelolco para la proscripción de las armas nucleares en la región. Gracias a esta reforma, en 
enero de 1994 Chile se incorporó plenamente al régimen establecido en este importante e innovador instrumento. También suscribió acuerdos regionales y globales para la proscripción de armas de destrucción masiva. Pasos como estos no solo contribuían a crear un entorno más estable y seguro en la región, sino que además respondían a la creciente preocupación mundial por el problema de la proliferación nuclear y de otras armas de destrucción en masa.

\section{MÁs AlLÁ de AMÉRICA LATINA: AMÉRICA DEL NORTE, EUROPA Y ASIA PACÍFICO}

En las últimas dos décadas, Chile logró consolidar sus relaciones con los principales socios políticos y económicos más allá de la región latinoamericana. De hecho, la firma de acuerdos económicos y el establecimiento de marcos permanentes de relacionamiento con Estados Unidos, Canadá, la Unión Europea y el Asia Pacífico representan uno de los grandes legados de política exterior de la Concertación. Se trata de un logro no menor, considerando que Chile destina más del $75 \%$ de sus exportaciones a los mercados extrarregionales y que más del $90 \%$ de su inversión extranjera procede de estos. En el ámbito político, la Concertación puso fin al aislamiento que gran parte de la comunidad internacional impuso al régimen militar que gobernó el país entre 1973 y 1990 . El resultado de este esfuerzo fue una inserción global y un protagonismo internacional que no se correspondió con el peso económico, estratégico y demográfico del país. A ello contribuyó también el éxito de un proceso de transición que inicialmente se veía difícil y lleno de hipotecas autoritarias y de un modelo económico que logró tasas notables de crecimiento para lo que había sido la historia económica del país.

Como no podía ser de otra manera, Estados Unidos ocupó un lugar importante en el diseño de la política exterior de la Concertación, aunque sería exagerado decir que fue uno de sus elementos definitorios. Más bien, a diferencia de algunos países de la región, Chile no definió su política exterior en función de los Estados Unidos. No buscó una alianza con la gran potencia ni tampoco consideró necesario sumarse a sus antagonistas y detractores en la región. Más bien, el objetivo fue desarrollar una relación estable y madura basada en intereses compartidos.

Cuando asumió el nuevo gobierno democrático, por primera vez en más de veinte años se presentaba la posibilidad de establecer unas relaciones normales y maduras, que superaran los desencuentros y tensiones del pasado y que a su vez pudieran conjugarse con las restantes prioridades de la política exterior. Fue así como, después de una larga espera, el año 2004 Chile logró finalmente firmar su Tratado de Libre Comercio (TLC) con Estados Unidos, el segundo suscrito por la gran potencia con un país latinoamericano. Desde los inicios de la transición democrática este 
acuerdo había sido visto, quizás exageradamente, como un elemento clave para la inserción global del país, pero esta meta se hizo esquiva durante muchos años debido a las dificultades de la política comercial de Washington. La larga espera fue aprovechada mediante un proceso de aprendizaje que culminó con la negociación del primer tratado de libre comercio de última generación, firmado con Canadá en 1996, país con el cual se alcanzó una gran sintonía tanto económica como política.

La nueva relación con los Estados Unidos también incluyó un alto nivel de diálogo político, que tuvo su prueba de fuego el año 2003, cuando el Presidente Lagos optó por no apoyar a los Estados Unidos en su búsqueda de una legitimación para la segunda guerra de Irak en el Consejo de Seguridad de las Naciones Unidas. El incordio se produjo poco antes de la conclusión de la negociación del ansiado TLC y al final solo se tradujo en una ceremonia de firma menos solemne. Este episodio comprobó la madurez que había alcanzado la relación bilateral chilenoestadounidense. En los últimos años, esta se ha orientado hacia la búsqueda de alianzas para la innovación y el desarrollo del capital humano, centradas no solo a nivel federal en los Estados Unidos sino que también en estados como California.

Un acervo histórico particularmente rico, una intensa corriente de afinidad política y la persistencia de considerables intereses económicos hicieron que Europa occidental y, en especial, los paí- ses que integran la Unión Europea (UE) se mantuvieran durante las últimas décadas como uno de los ejes principales de las relaciones internacionales de Chile. Desde la perspectiva chilena, Europa siempre había ejercido una atracción especial sobre un amplio espectro de los círculos políticos e intelectuales del país. Los modelos y doctrinas europeas sirvieron como fuente de inspiración de numerosos partidos y corrientes políticas nacionales y los desarrollos institucionales del Viejo Continente invariablemente han despertado el interés de políticos y académicos. El hecho de que el espectro político chileno tuviera tradicionalmente una configuración cercana a la europea condujo al establecimiento de vínculos significativos entre los partidos y las principales corrientes políticas europeas.

Básicamente, la estrategia chilena apuntó a aprovechar el activo común de las relaciones mutuas de una mejor manera, transformando la afinidad que existía especialmente en el ámbito político en un vínculo más estrecho y mejorado cualitativa y cuantitativamente. En una etapa en que la UE se profundizaba y reconsideraba sus vínculos con los países que formaban su entorno más cercano, Chile logró negociar un Acuerdo de Asociación con la UE que descansa en un pilar económico, que comprende un TLC, un pilar de diálogo político y otro de cooperación. El acuerdo fue firmado el año 2002, proporcionando un marco sólido y estable para el desarrollo de las relaciones con esa agrupación. Esta 
experiencia fue complementada mediante iniciativas bilaterales con países como Alemania, Francia, España, Italia y otros. El acuerdo con la UE sirvió también de referente para posteriores negociaciones con los países de la Asociación de Libre Comercio Europea (EFTA, en inglés) y Turquía.

En la actualidad, los esfuerzos respecto de la UE apuntan a ampliar las bases de cooperación hacia materias como la innovación, la ciencia y tecnología, el capital humano y las energías renovables, bajo el concepto de una "Asociación para el Desarrollo y la Innovación”.

Aunque hay antecedentes históricos que demuestran la existencia de un interés precoz de Chile en la Cuenca del Pacífico, históricamente Chile tendió a mirar más hacia el resto de América Latina, América del Norte y Europa. Pero a partir de los años setenta se empezó a perfilar un esfuerzo para relacionar al país más estrechamente con la Cuenca del Pacífico, apoyado en una realidad geográfica indesmentible, la ubicación estratégica del país en el Pacífico Sudeste, la proyección que daba la Isla de Pascua y la existencia de vínculos comerciales de larga data con Japón y crecientemente, la República Popular China. Los gobiernos de la Concertación no desaprovecharon este esfuerzo. Pese a que las prioridades iniciales estaban más orientadas hacia las Américas y Europa, muy pronto se tomó conciencia de la relevancia económica y política de la Cuenca del Pacífico en el nuevo sistema internacio- nal. Los intercambios políticos de alto nivel aumentaron, Asia se convirtió en el principal mercado para las exportaciones chilenas, superando a Estados Unidos, la UE y América Latina y las representaciones diplomáticas y comerciales se expandieron.

En consonancia con ese interés, Chile desplegó una ofensiva diplomática para obtener su incorporación al prestigioso foro APEC, entidad gubernamental del más alto nivel considerada como el núcleo de la organización regional más importante del área.

Pero la política hacia el Asia-Pacífico no se limitó al ámbito multilateral y económico. También se desarrolló un esfuerzo importante para consolidar los vínculos bilaterales. Para ello, había que tomar en cuenta que el Asia-Pacífico escondía una fuerte diversidad económica, política y cultural, incluyendo países altamente desarrollados y países en desarrollo; democracias avanzadas, regímenes autoritarios y sistemas de partido único; antiguas civilizaciones y culturas de raíces claramente occidentales. De esta manera, se mantuvo un enfoque diferenciado hacia el área, que implicó consolidar las relaciones tradicionales que mantenía el país con potencias como Japón, aprovechar el potencial de la vinculación con la República Popular China, que se convirtió en el primer mercado para las exportaciones chilenas, desarrollar fuertemente las relaciones con una potencia emergente como Corea, que se había transformado en unos pocos años en un relevante socio comercial de Chile. Con estos tres 
países Chile logró negociar tratados de libre comercio. El mismo objetivo fue planteado respecto de India, otro gran socio asiático, habiéndose negociado un acuerdo de alcance parcial a la espera de nuevas definiciones de política comercial en Delhi. Por otra parte, el progreso de las economías de la ASEAN, unido al avance de esta entidad regional, hizo que se prestara atención especial a las relaciones con sus integrantes, destacándose especialmente el caso de Singapur, país asociado a Chile mediante un TLC, y las crecientes relaciones con Indonesia, Malasia, Tailandia y Vietnam. También se potenciaron las relaciones con Australia y Nueva Zelandia mediante sendos acuerdos de libre comercio. Cabe agregar que ambos países son vistos como like-minded, en consideración a las coincidencias que se observaron con ellos en el ámbito de las políticas públicas, y como socios naturales en la búsqueda de asociaciones productivas innovadoras.

El buen estado de las relaciones de Chile con el mundo desarrollado facilitó también su incorporación, a partir del año 2010, a la Organización para la Cooperación y el Desarrollo Económicos (OCDE), luego de una serie de negociaciones y exigentes exámenes de políticas públicas.

\section{Multilateralismo: las RESPONSABILIDADES GLOBALES}

La participación en el sistema multilateral siempre representó un aspecto fundamental de la política exterior y de la inserción de Chile en el mundo. Asumiendo que el país no podía pretender modificar por sí solo una situación regional o global desfavorable para sus intereses nacionales, la política exterior privilegió la acción de las organizaciones internacionales y los mecanismos colectivos para resolver los problemas regionales o globales que interesaban a Chile. En su calidad de país dotado de una economía relativamente pequeña y en desarrollo, Chile había depositado grandes expectativas en la política multilateral, transformándose en un miembro particularmente activo de diversas organizaciones regionales y globales, aportando una visión propia e ideas creativas. El hecho de que esta tradición haya contenido visiones un tanto utópicas no impidió alcanzar objetivos de gran utilidad para el país, incluyendo la extensión de su frontera marítima, la protección de sus intereses antárticos o un flujo de recursos de cooperación técnica que, en su día, asumió mucha relevancia. Esta tradición histórica se reafirmó durante las décadas de la Concertación.

Una serie de asuntos que preocupaban a Chile necesitaban de tratamiento multilateral, tanto más en una etapa en que se modificaban los regímenes internacionales en áreas tan cruciales como la paz y la seguridad, la defensa de la democracia y de los derechos humanos, el comercio, la protección del medio ambiente, el cambio climático, la lucha contra el narcotráfico, el terrorismo, la cooperación para el desarrollo 
económico y social y la contención de las grandes crisis financieras. En varios casos, el multilateralismo se vio reforzado por la participación directa de la sociedad civil chilena en los foros internacionales, que constituye una expresión poco reconocida de la propia globalización, que dista mucho de ser un fenómeno meramente económico.

Es cierto que las expectativas que se depositaron inicialmente en la emergencia de un nuevo multilateralismo no se vieron cumplidas en toda su extensión. Pero también es cierto que se inició un importante proceso de reformas y renovación en esta área, en el que Chile pudo participar. Chile apoyó el papel que asumieron las Naciones Unidas en materia de prevención y contención de conflictos internacionales, participando en las operaciones de paz en IrakKuwait, El Salvador, Camboya, BosniaHerzegovina (luego traspasada a la UE), Timor Oriental, y, en lo que representó un salto cualitativo en consideración al esfuerzo involucrado, Haití, en este último caso en una acción conjunta con un número creciente de países latinoamericanos. En un marco distinto, Chile también participó en la Misión de Observadores Militares Ecuador-Perú, que contribuyó a resolver un conflicto bélico ocurrido en los años noventa entre ambos países.

La política exterior también puso gran énfasis en la incorporación del país en los regímenes internacionales vigentes o en proceso de negociación en materia de desarme y proscripción de armas de destrucción en masa. Chile participó activamente en el establecimiento de la Organización Internacional para la Prohibición de las Armas Químicas, adoptando las medidas internas necesarias para dar cumplimiento a los exigentes compromisos contenidos en la Convención que le dio origen. En 1995 el país adhirió finalmente al Tratado de No Proliferación Nuclear, poniendo fin a una postura doctrinaria que rechazaba este acuerdo debido a que sus efectos no eran aplicables a las potencias nucleares. Esta reticencia fue observada inicialmente por varios países de la región y del resto del mundo, pero con el tiempo se fue haciendo más excepcional y contradictoria, ya que Chile compartía fuertemente el interés de evitar la emergencia de nuevas potencias nucleares en el mundo. Asimismo, en 1996 Chile se convirtió en uno de los primeros firmantes del Tratado de Proscripción Total de los Ensayos Nucleares. Ese mismo año, Chile ingresó, junto a otras naciones, a la Conferencia de Desarme. En 1997, el país fue uno de los firmantes originarios de la Convención para la Proscripción de las Minas Antipersonales, uno de los instrumentos de desarme más innovadores y publicitados de los últimos años. Esta decisión implicó asumir el compromiso de remover estas armas de regiones fronterizas, con todos los costos que ello implicaba. Igualmente, Chile respaldo las iniciativas para perfeccionar los regímenes de salvaguardias contemplados en los acuerdos relacionados con la no proliferación y el desarme nuclear, firmando por ejemplo 
el Protocolo Adicional al Régimen de Salvaguardias de la Organización Internacional de Energía Atómica (OIEA). En suma, en unos pocos años Chile no solo dejó de ser un país díscolo en materia de regímenes globales de desarme y desnuclearización, sino que se ubicó entre los países de vanguardia en este ámbito.

La política multilateral de Chile siguió orientándose hacia su territorio antártico y los espacios marítimos y aéreos en que ejerce soberanía o cuya adecuada protección le ha afectado directamente. En el caso del sistema del Tratado Antártico, cabe hacer especial mención al Protocolo de Madrid, firmado en octubre de 1991, que constituye una importante fuente de compromisos, ya que su normativa estipula que toda actividad en el continente blanco deberá someterse a una evaluación de impacto ambiental, lo que ha determinado un costo adicional en el accionar en el continente helado.

En materia marítima, Chile ratificó en 1997 la Convención de las Naciones Unidas sobre el Derecho del Mar, culminando así un esfuerzo diplomático que se había iniciado en 1947 y en el que habían participado todos los gobiernos que tuvo el país. El instrumento representó uno de los ejemplos más claros de la emergencia de un nuevo régimen internacional en el que Chile y otros países medianos y pequeños pudieron hacer un aporte decisivo. Pero el instrumento tuvo también sus limitaciones. Una de ellas se refiere a la regulación de las especies transzonales y altamente migratorias que se hallan más allá de las 200 millas marinas y que no están debidamente cauteladas en la normativa internacional. Este problema ha requerido de una atención especial, en consideración a la importancia económica que asume la pesca en el país. De allí que Chile haya negociado activamente la constitución de una organización regional de pesca en el Pacífico Sur y haya buscado, con éxito limitado, la adopción de medidas provisionales para controlar la sobreexplotación de varias especies en el área, especialmente por los pesqueros de aguas distantes. Asimismo, ha intentado buscar acuerdos concretos con otros países en esta materia, principalmente en el marco de la Comisión Permanente del Pacífico Sur.

La política multilateral debió enfrentar un nuevo desafío en el ámbito de la protección del medio ambiente, tema que ha entrado de lleno en la agenda internacional. Las cuestiones medioambientales cubren un espectro amplísimo de nuestra proyección internacional, que incluye el cambio climático, las políticas marítima y antártica, las negociaciones económicas internacionales, las exportaciones de commodities, el transporte de sustancias tóxicas y potencialmente peligrosas y de cargas nucleares, el depósito de desechos, las inversiones extranjeras, las obras públicas y la política forestal. Ella también está muy ligada a la defensa de los pueblos indígenas, tema extraordinariamente complejo que también se ha empezado a plantear de manera incipiente en las relaciones exteriores de Chile. 
Chile participó con intensidad en los principales foros medioambientales, como lo fue la histórica Conferencia Cumbre sobre Medio Ambiente y Desarrollo, celebrada en Río de Janeiro en 1992, o las Cumbres sobre Cambio Climático, celebradas en Kyoto en 1998 o en Copenhague el 2009. No fue fácil conciliar en estos foros la legítima preocupación y la urgente búsqueda de medidas para enfrentar estos desafíos con las necesidades del crecimiento económico y energía y la asunción y distribución de los enormes costos involucrados en estos esfuerzos.

\section{Conclusiones}

Las prioridades reseñadas no agotaron necesariamente la política exterior de los gobiernos de la Concertación. Chile mantuvo también su presencia en países seleccionados de otras áreas del mundo -Medio Oriente, Magreb, Rusia, África Austral- y se ocupó de un sinnúmero de temas en los foros e instituciones más diversas. Sin embargo, también se esforzó en jerarquizar crecientemente sus prioridades, tarea nada fácil para la política exterior de un Estado relativamente pequeño, que se ve constantemente sometido al juego de factores y verdaderos lobbys externos e internos que se movilizan en favor de intereses de política exterior extraordinariamente diversos.

La intensa actividad internacional que desplegó el país requirió de la adaptación de los instrumentos de la política exterior. Esta necesidad parecía patente en la Cancillería, pero también se extendía a otras áreas del gobierno e incluso del sector privado. Los gobiernos de la Concertación adoptaron un enfoque gradualista para adaptar y fortalecer los instrumentos de la política exterior, procurando hacerlos más efectivos, modernos e integrados. Este objetivo implicó la introducción de transformaciones en la institucionalidad de la política exterior. Concretamente, requirió de una Cancillería organizada de acuerdo a áreas geográficas y grandes temas funcionales que superara la tradicional división entre asuntos políticos y económicos, dotada de personal diplomático y profesional calificado y de métodos de gestión innovadores. En la práctica, sin embargo, se pudo hacer una reestructuración parcial dentro del marco legal existente, que implicó la creación de nuevas unidades y la supresión de otras, una cierta racionalización de la gestión presupuestaria, el desarrollo de programas de capacitación, la creación de equipos negociadores altamente profesionalizados en la Dirección General de Relaciones Económicas Internacionales, la renovación de la agencia de promoción de exportaciones (ProChile) y el establecimiento y posterior vinculación a la Cancillería de la AGCI. Es obvio que quedó mucho por hacer y que hicieron falta cambios más profundos. Pero también es importante evaluar lo que se hizo. Hoy parece casi natural que el país haya estado embarcado durante veinte años en un proceso constante de negociaciones económicas internacio- 
nales, pero es importante recordar que los equipos que las condujeron no existían al comienzo de los años noventa. Se trató de una profesionalización de la gestión externa que normalmente se pasa por alto. Por su parte, el Servicio Exterior exhibió un nivel de profesionalismo plenamente comparable al de las Cancillerías más establecidas de la región y se vio complementado por el concurso de algunos especialistas dotados de una indiscutible versación en los temas de la política exterior, que habían estado marginados de la Cancillería durante el período autoritario que vivió el país.

Por cierto, se pudo innovar más. Pero es importante tener en cuenta que las urgencias de la política exterior fueron otras. Además, una reforma de la Cancillería necesitaba también de un referente más general en todo el sector público. Sin embargo, la reforma del Estado chileno quedó pendiente y probablemente significaba abrir un frente conflictivo dentro de una transición democrática inicialmente compleja. Por último, las reformas son propensas a conflictos políticos, gremiales y corporativos. Chile no fue una excepción en esa materia.

En general, la política exterior de los gobiernos de la Concertación aportó un balance favorable. Esa es también la percepción de la opinión pública que virtualmente en todas las encuestas evaluó de manera especial- mente positiva las relaciones exteriores del país, haciendo de ellas una de las políticas públicas que más aprobación suscitaron. Es importante agregar que esta evaluación no derivó de uno o dos hitos específicos, sino más bien de una labor general. Por cierto, el balance no es igualmente favorable en todos los campos. La política vecinal se enfrentó a limitaciones objetivas y la agenda histórica siguió más abierta de lo que se podría haber previsto. Las relaciones con América Latina se vieron limitadas por polarizaciones ideológicas regionales de las que en todo caso Chile procuró marginarse.

La política exterior proyecta valores y es, en buena medida, un reflejo de la política interna. Pero ella también cumple una función esencial de adaptación a las cambiantes condiciones que caracterizan al sistema internacional. El balance que aportan estos veinte años comprueba que el país logró adaptarse a su nuevo contexto externo y que fue este contexto el que proporcionó la principal fuente de cambios de la política exterior. Ella respondió más a los estímulos externos que a las necesidades de la política interna o las características de un determinado gobierno. Por lo mismo, es probable que gran parte de las tendencias centrales reseñadas en este trabajo se mantengan bajo un gobierno de cuño distinto como el que asumió en marzo del 2010. 